\title{
The Influence of Irradiation and Temperature to the Nature of Crosslinking in Isoprene Nitrile Elastomer
}

\author{
Shiraz M. Mammadov", Rena F. Khankisiyeva, Jovdat S. Mammadov, Adil A. Garibov, \\ Revan N. Mehdiyeva
}

Institute of Radiation Problems, Azerbaijan National Academy of Sciences, Azerbaijan

Copyright (C) 2015 Horizon Research Publishing All rights reserved.

\begin{abstract}
The increase of irradiation temperature by gamma-rays of emulsion isoprene nitrile elastomer in the range of $298-423 \mathrm{~K}$ is accompanied by the significant increase of crosslinking rate and strength deterioration of unfilled cures at the same time. By the method of sol-gel analysis, the output dependences of the mesh chains $\left(1 / \mathrm{M}_{\mathrm{c}}\right)$, cross-linked molecules $\left(1 / \mathrm{M}_{\eta \mathrm{t}}\right)$ and crosslinks $\left(\mathrm{n}_{\mathrm{c}}\right)$ for isoprene nitrile elastomer are determined between 298 and $423 \mathrm{~K}$. The influence of acrylonitrile content of elastomer group during the process of irradiation and temperature on density change of curing grid using Fourier spectroscopy is established. It also studied the molecular structure of isoprene nitrile elastomer and unsaturation at irradiation and temperature (423K, $500 \mathrm{kGy})$.
\end{abstract}

Keywords Isoprene Nitrile Rubber, Irradiation, Crosslinking, Temperature, Rheology, Curing

\section{Introduction}

It is known that exposure of elastomers under high intensity radiation may be accompanied by a significant rise of samples temperature [1-7]. In some cases to accelerate the process of radiation curing simultaneous heating of the samples is recommended [8-14]. The most part of elastomers refers to polymers of cross-linked type, however, the tendency to form the crosslinks and the number of cross-linked molecules of various type elastomers is varied and determined by the chemical structure of polymer chain, polymer morphology and irradiation conditions. Moreover, the process efficiency of radiation crosslinking is largely dependent on the method of elastomer preparation.

It is known that the radiation-chemical yield of cross-linking and formation of effective transverse chemical bonds in butadiene nitrification elastomers depends on the dose power and the absorbed dose. For increasing the crosslinks yield and to accelerate radiation-chemical reactions occurring in elastomers the specific role belongs to environment [15-19]. Thus, there is data concerning the use of air to activate radiation-chemical process in butadiene nitrile rubbers [20-24]. It was established that in presence of oxygen environment the radiation-chemical yield of cross-linked molecules increases 1.5 times, along with this the crosslinks depends on the nature of elastomer. [23]. It should be noted that the output of crosslinking and effective crosslinks increases under the influence of irradiation temperature. As a result of this formed elastomers may contain crosslinks of different energies. Also it is particularly important to carry out and to choose the irradiation technology of samples in order to obtain optimum elastomer properties at lower doses of irradiation [25-30].

However the process of thermoradiation impact on isoprene-nitrile elastomer has not yet been studied. There are only a tear-off data on the effect of crosslinking rate on increase of irradiation temperature for butadiene nitrile rubbers till $423 \mathrm{~K}[20]$.

Systematic relationship study of radiation-chemical changes (crosslinking, degradation, and change in the yield of crosslinks, mesh chains number, viscosity, sol fraction, and the change in the content of double bonds) and the characteristics of the physical and mechanical properties of elastomers under the heat and radiation exposure have not been conducted up to present. In this article, the experiments result in the effect of temperature on radiation crosslinking of isoprene nitrile using a sol-gel method of analysis based on the laws of the static theory of nets structure.

\section{Experimental}

As an object of study was the isoprene nitrile elastomer (INE-30) obtained by the method of emulsion polymerization. According to results of the study, by the method of Fourier spectroscopy and the butadiene portion of polymer at $303 \mathrm{~K}$ of polymerization, isomeric composition of double binds in observed polymer is 1,2-isomer 11,4\%, 1,4-isomer $17.1 \%$ and trans-1,4-isomer $71,5 \%$. Due to changes in molecular structure during the radiolysis of isoprene-nitrile elastomer (molecular weight distribution and grid density), before the conduction the radiative processes 
in elastomer pre-determined by viscometric molecular weight and polydispersity $\left(\mathrm{M}_{\mathrm{n}}=81000, \mathrm{M}_{\mathrm{w}}=238000\right.$, $\mathrm{M}_{\mathrm{w}} / \mathrm{M}_{\mathrm{n}}=2,9$ ).

Samples with $1 \mathrm{~g}$ weight were placed in the glass ampoules. Then they were evacuated for 3 hours until a residual pressure of $25 \cdot 10^{3} \mathrm{~Pa}$. Radiolysis of soldered ampoules (evacuated) containing the sample was subjected with gamma-rays $\mathrm{Co}^{60}$ at 293,373 and $473 \mathrm{~K}$ and at the power of absorbed energy $4.9 \mathrm{~Gy} / \mathrm{s}$ (according to the data of ferro sulphate dosimetry). For avoiding oxidation during irradiation of samples which had the form of plates with thickness $1 \mathrm{~mm}$ during extrusion, they were covered by aluminum foil. Indeed, the Fourier comparison of infrared spectra and data of the sol-gel analysis, irradiated with evacuated ones up to $2.5 \cdot 10^{-3} \mathrm{Hg}$ showed complete absence of oxidation and the same degree of crosslinking in both cases.

Structural parameters (concentration of crosslinks, the number of cross-linked molecules) and the nature of the mesh density of the thermal irradiated samples were determined by sol-gel analysis and calculated by the equation of Flory-Rehner. Research methods of Fourier spectroscopy by Varian 640-IR FT-IR Spectrometer and mechanical tests are described in detail [31-32].

The absorbed dose in the samples was calculated by comparing the electron density in observed dosimetric systems [33]. Inherent viscosity of irradiated elastomer was determined in toluene at $293 \mathrm{~K}$ by a known method on Ubbelohde viscometer. The calculations were performed by Mark Houwink $[\eta]=\mathrm{kM}^{\alpha}$, constant value $\mathrm{K}=4,9 \cdot 10^{4}$ and $\alpha=0,64$ (for toluene) [34-35].

According to the data of sol-gel analysis it is evaluated the relative change in crosslinking yield of $G_{c}$ and $G_{g}$ [32] degradation with increasing irradiation temperature from $298 \mathrm{~K}$ to $423 \mathrm{~K}\left(\mathrm{G}_{\mathrm{c}}{ }^{100} / \mathrm{G}_{\mathrm{c}}{ }^{25}, \mathrm{G}_{\mathrm{c}}{ }^{150} / \mathrm{G}_{\mathrm{c}}{ }^{25}\right)$ and up to $473 \mathrm{~K}$ $\left(\mathrm{G}_{\mathrm{c}}{ }^{200} / \mathrm{G}_{\mathrm{c}}{ }^{25}\right)$ (table 1$)$.

Table 1. The value of crosslinks yield and the act of destruction of irradiated isoprene nitrile elastomers depending on the temperature

\begin{tabular}{|c|c|c|c|}
\hline $\begin{array}{c}\text { Isoprene nitrile with } \\
\text { acrylonitrile } \\
\text { content, } \%\end{array}$ & $\begin{array}{c}\text { Heat } \\
\text { temperature, } \mathrm{K}\end{array}$ & $\mathrm{G}_{\text {cross }}$ & $\mathrm{G}_{\text {dest }}$ \\
\hline \multirow{2}{*}{10} & 298 & 3,5 & - \\
& 373 & 7,8 & - \\
& 423 & 11,3 & - \\
& 473 & - & 1,5 \\
\hline \multirow{2}{*}{20} & 298 & 4,8 & - \\
& 373 & 9,1 & - \\
& 423 & 14,7 & 3,2 \\
\hline \multirow{2}{*}{30} & 473 & - & - \\
& 298 & 5,7 & - \\
& 373 & 11,3 & 4,3 \\
\hline
\end{tabular}

Changing the content of double bonds was evaluated as during elastomers obtaining at $500 \mathrm{kGy}$ and when the density of the grid at the same irradiation temperatures of 298 and $473 \mathrm{~K}$. Upon receipt of the same mesh density at various temperatures the doses distinguish between themselves
(Table 2).

Table 2. Consumption of double bonds in irradiated isoprene nitrile elastomers.

\begin{tabular}{|c|c|c|c|c|c|}
\hline \multirow{2}{*}{$\begin{array}{c}\text { Isoprene } \\
\text { nitrile with } \\
\text { acrylonitrile } \\
\text { content, \% }\end{array}$} & \multirow{2}{*}{$\begin{array}{c}\text { Heat } \\
\text { temperature, } \\
\mathrm{K}\end{array}$} & \multirow{2}{*}{$\begin{array}{c}\text { Number } \\
\text { of chain } \\
\text { net, } \\
1 / \mathrm{M}_{\mathrm{c}} \cdot 10^{5}, \\
\mathrm{~mol} / \mathrm{cm}^{3}\end{array}$} & \multicolumn{3}{|c|}{ Flow rate of double bonds } \\
\hline & & & 1,4-trans & 1,4-cis & 1,2 \\
\hline \multirow{4}{*}{10} & 298 & 3,8 & 0,54 & 0,34 & 0,6 \\
\hline & 373 & 4,6 & 0,61 & 0,41 & 0,9 \\
\hline & 423 & 5,9 & 0,72 & 0,54 & 0,21 \\
\hline & 473 & 17 & - & - & - \\
\hline \multirow{4}{*}{20} & 298 & 4,3 & 0,63 & 0,27 & 025 \\
\hline & 373 & 5,0 & 1,1 & 0,43 & $\begin{array}{l}0,25 \\
0,57\end{array}$ \\
\hline & 423 & 7,4 & 1,8 & 0,66 & $\begin{array}{ll}0,51 \\
0,68\end{array}$ \\
\hline & 473 & - & - & & \\
\hline \multirow{4}{*}{30} & 298 & 5,4 & 1,4 & 0,56 & 0,42 \\
\hline & 373 & 9,7 & 1,8 & 0,98 & 0,74 \\
\hline & 423 & 12,1 & 2,1 & 1,1 & 0,81 \\
\hline & 473 & - & - & - & - \\
\hline
\end{tabular}

\section{Results and Discussion}

Under the influence of irradiation and temperature INE-30 structure undergoes significant changes that affect the nature and content of double bonds. As a result of crosslinking of elastomer macromolecules a spatial grid is formed. Equations adjustment of high elasticity theory gave the possibility to use them primarily for a qualitative assessment of molecular weight and the average number molecular weight of the sol fraction.

Figure 1 shows the data of intrinsic viscosity changes of isoprene nitrile elastomer under the simultaneous action of temperature $(298-473 \mathrm{~K})$ and irradiation $(\mathrm{D}=500 \mathrm{kGy})$.

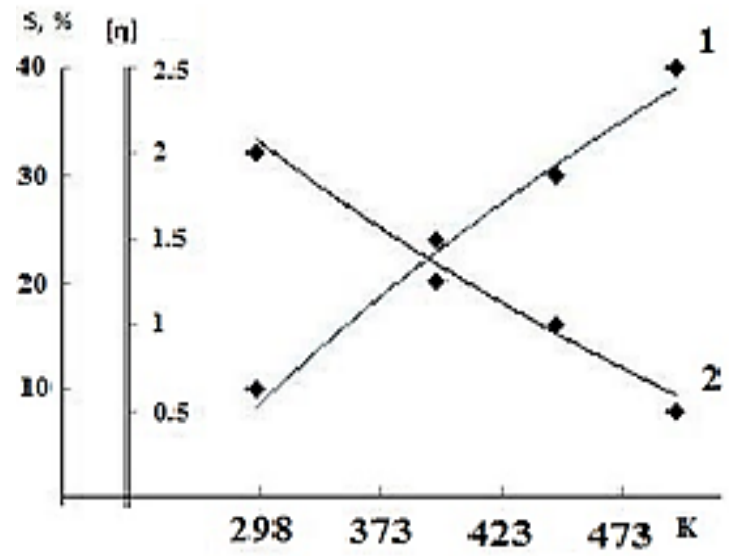

Figure 1. Dependence of intrinsic viscosity (1) and content of sol-gel fraction (2) with temperature ( $D=500 \mathrm{kGy})$.

Figure 1 shows that for INE at $298 \mathrm{~K}$ the intrinsic viscosity is 0.2 . With increase of temperature the molecular weight of elastomer is also increased. Significant increase in molecular weight was observed between 373 and $423 \mathrm{~K}$, and the intrinsic viscosity rises from 0.4 to 2.3. With increasing of irradiation $(473 \mathrm{~K})$ temperature the intrinsic viscosity decreases (fig. 1, curve 1). The reduction of INE 
molecular weight is a result of degradation of the main chain of polymer. During the viscosity increasing in temperature range between 298 and $423 \mathrm{~K}$, the elastomer becomes completely insoluble, indicating the molecules crosslinking of polymer chains.

Data presented in the figure 1 show that the sol fraction at different degrees of grid density is decreased (curve 2). Decreasing of sol fraction indicates a homogeneous distribution of cross-links in elastomer molecules [31, 36, 37]. Such a notion of grid homogeneity in elastomers was previously put forward on the basis of some data.

As table 1 shows the crosslinking outputs $\left(\mathrm{G}_{\mathrm{c}}\right)$ at temperature increasing up to $423 \mathrm{~K}$, the value increases for 2-3 times in all samples. Above $423 \mathrm{~K}$ it is observed the chain destruction of isoprene nitrile elastomer. At a dose of $500 \mathrm{kGy}$ and $298 \mathrm{~K}$, at temperatures between 373 and $423 \mathrm{~K}$ there is a noticeable change in the content of double bonds in all isoprene nitrile isomers. The sharp increase of the cross-links yield of chains (table 1) can be explained by the increase in consumption of double bonds.

Acrylic nitrile links in isoprene chain have protective effect, which manifests itself in a decrease in the yield of cross-links and degradation (table 1). The effect of irradiation temperature on crosslinking yield is associated with the phase state of elastomer; wherein for elastomers being in elastic state the crosslinking rate increases with temperature increase. If the chains are more stiffness, the cross-linking outputs are lower. Besides, the main factors affecting the efficiency of cross-linking experiments are changing the spatial grid of elastic polymer and the environment. The effect of irradiation temperature on the parameters of the spatial grid, molecular structure and unsaturation was investigated by the method of Fourier spectroscopy.

In area of dense grids, at which the mechanical properties of vulcanizates are compared, the variation amount of cis-unsaturation is within the accuracy of the method. For quantitative comparison of unsaturation changes the samples were irradiated at 298 and $423 \mathrm{~K}$, till the obtaining the density grid $1 / \mathrm{M}_{\mathrm{c}}=12 \cdot 10^{-5} \mathrm{~mole} / \mathrm{cm}^{3}$, that corresponds to 500 $\mathrm{kGy}$ at $298 \mathrm{~K}$. The use of such large doses for comparison is justified, since the change rate of unsaturation remains constant in a wide range of doses.

Fourier analysis of the infrared spectrum shows (figure 2) that the temperature exposure causes some significant changes. It is also observed a change in the intensity of absorption bands at $730 \mathrm{~cm}^{-1}$ corresponding to the double bonds in the 1,4 cis-configuration and $965 \mathrm{~cm}^{-1}$ corresponding to the configuration of the double bonds. [38]. Alterations in these bands can be explained by cis-trans isomerization in elastomer, and consumption of the double bonds [39]. Calculations have shown that during irradiation at $298 \mathrm{~K}$ there is a reduction of cis-unsaturation to $4 \%$, including $3 \%$ goes to isomerization and only $1 \%$ is spent. Increasing of irradiation temperature up to $423 \mathrm{~K}$ leads to reduction of cis-unsaturation at $9 \%$, of which $5 \%$ goes to isomerization, and $4 \%$ is spent.

During the conducted work some data was obtained on influence of effect of irradiation temperature on unfilled vulcanizates. It is shown that at the lower dense grids of strength at the optimum the curing is markedly reduced (fig. $3)$.

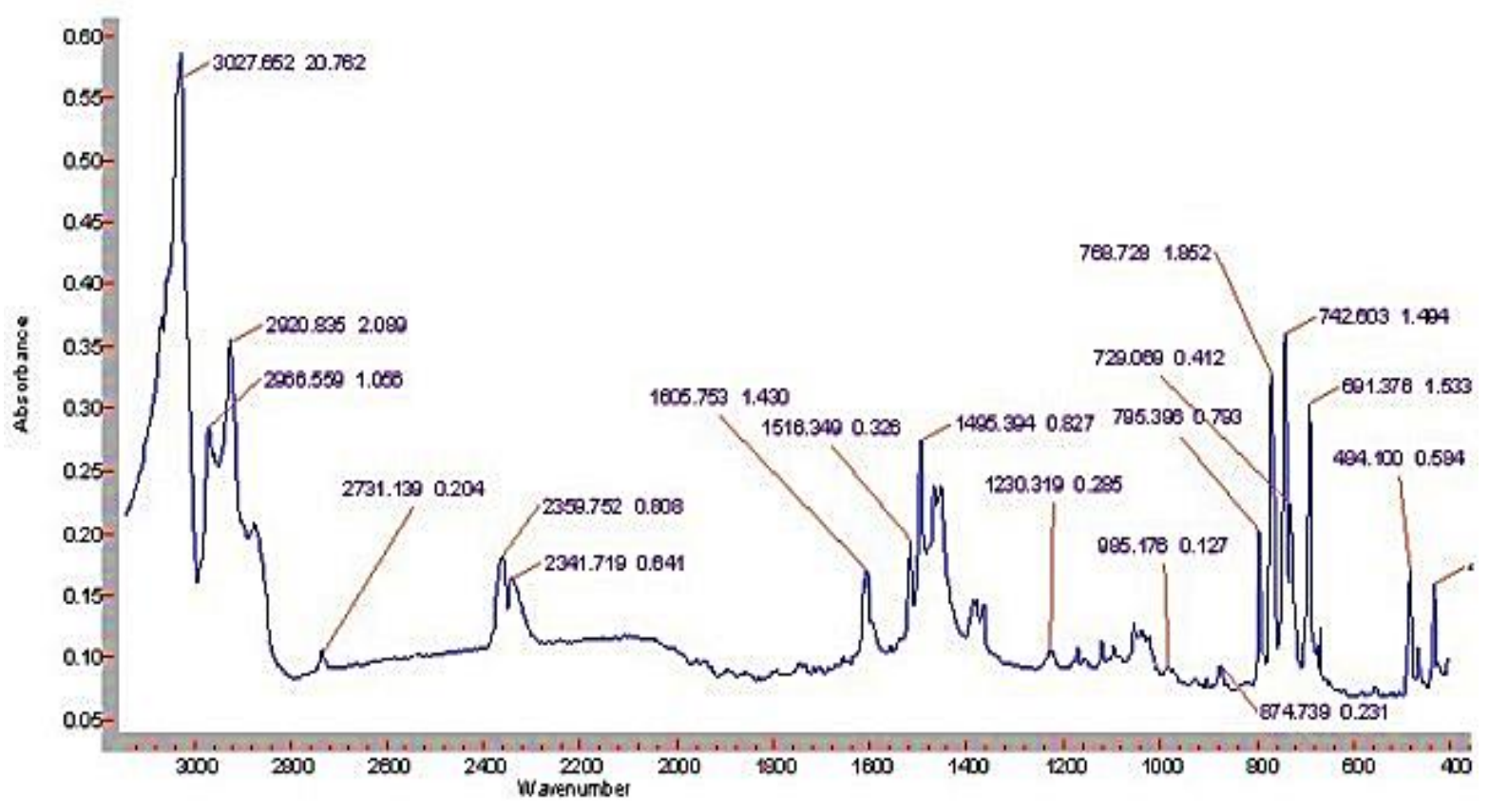

Figure 2. The IR spectra of unsaturated elastomers. 


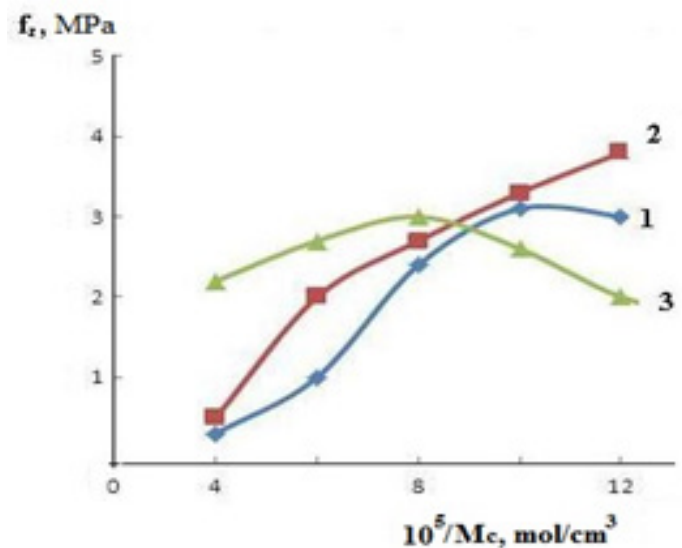

Figure 3. The dependence of strength density on vulcanization grid (number of chains in grid) in isoprene nitrile elastomer by irradiation at 298 (1), 373 (2) and 423 (3) K.

Thus, the increasing of irradiation temperature up to $423 \mathrm{~K}$ decreases the mechanical properties of cures, which contributes a significant drop of unsaturation and at the same time the crosslinks output increases rapidly (figure 4).

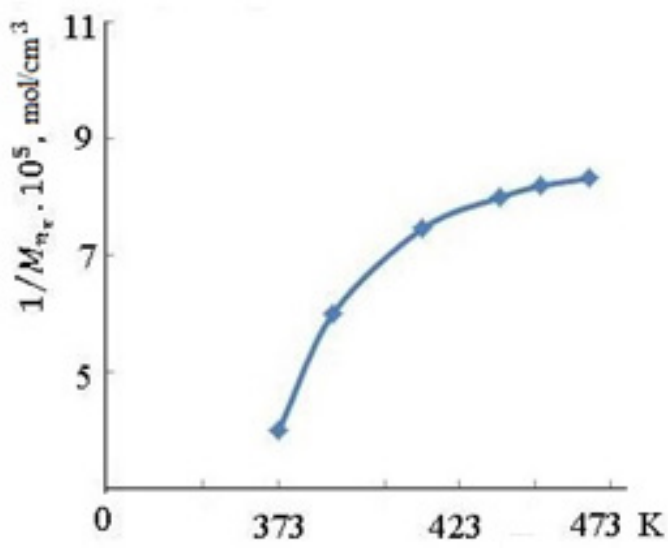

Figure 4. Dependence on concentration output of links of irradiated IN of temperature

Sol-gel analysis shows that the temperature increase leads to further degradation of isoprene nitrile elastomer. Therefore, destruction is not the cause of the observed changes in properties of cures. Increase of unsaturation consumption with increasing of temperature, obviously not related to oxidation. The increase of unsaturated consumption could be associated with the formation of intermolecular cycles. However, this assumption is contradicted by the fact that the fall of unsaturation is accompanied by a significant increase of cross-linked molecules to form the cross-links.

From the data in figure 5 it can be seen that the formation of crosslinks in isoprene nitrile elastomer proceeds rapidly depending on the irradiation temperature. The effective yield of cross-links at $423 \mathrm{~K}$ is 13.0 per $100 \mathrm{eV}$, further the degradation occurs at $443 \mathrm{~K}$. Obviously the consumption of double bonds (unsaturated) is associated with the formation of intermolecular cross-links.

If we consider the individual case where all cross-links are formed as a result of disclosure of the double bonds, then a simple calculation shows that the consumption of double bonds in elastomer at a dose of $500 \mathrm{kGy}$ and $423 \mathrm{~K}$ would be $1.5-2.0 \%$. The analysis of the structural parameters of cures grid showed that the number of cross-linked molecules in cures is not very high and at $423 \mathrm{~K}$ is $7,4 \mathrm{~mole} / \mathrm{cm}^{3}$. In all experiments while determination of the structural parameters of grid the reduction and decay of intermolecular bonds took place at the same temperature $(473 \mathrm{~K})$. Thus, data comparison on change the nature of the cross-links output, cross-links of chain mesh, consumption of double bonds and Fourier spectroscopy analysis shows that the increase of irradiation temperature by gamma rays in isoprene nitrile elastomer in the range of $298-423 \mathrm{~K}$ is accompanied by a significant increase in the rate of cross-linking and at the same time, the deterioration of the strength of unfilled cures. It is shown that during the unsaturation decrease in elastomer and sensitivity increase to irradiation the growth parameter of the grid circuit in the temperature range of $298-423 \mathrm{~K}$ takes place. However, the mechanisms of thermic and radiation processes responsible for the observed changes in the properties needs to be observed in future (figure 5).

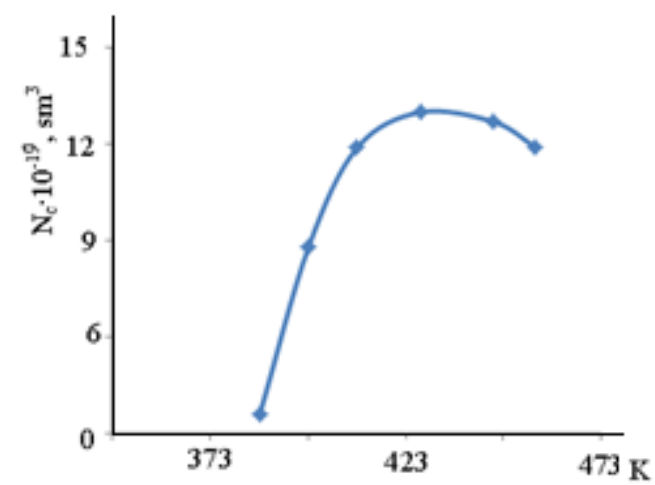

Figure 5. Dependence of output crosslinks of INE irradiated at 298, 373 and $423 \mathrm{~K}$

\section{Conclusions}

As a result of conducted research concerning the effect of irradiation temperature on character of isoprene nitrile elastomer it can be described as follows. Important factors affecting the efficiency of cross-linking are: temperature and radiation, spatial grid and supramolecular structure of elastomer, the yield of crosslinks namely depends on the packing of molecules and the presence of double bonds. Otherwise the study on initiation and extra temperature effect promote an additional crosslinking that causes the $\mathrm{C}-\mathrm{C}$ formation of chemical bonds in macromolecules of isoprene nitrile elastomer.

As a result of temperature increasing at a constant dose it effects on the yield increase of chains grid number and cross-links, which leads to an intermolecular reaction. Probably the process takes place in an elastic medium because isoprene nitrile elastomer is unsaturated polymer, 
the lowest ionization potential have the carbon atoms involved in formation of double bonds. In this case during the formation of cross-links in each act of crosslinking the active site is regenerated, which may be involved in formation of the spatial grid.

The obtained results make it possible to conduct the directed research in the field of thermic and radiation crosslinking of elastomers with presence of quasi and multicomponent systems for obtaining of elastomeric materials with valuable properties.

Research thermic and radiation curing instead of thermal one allows to get rid of the peroxide used as a crosslinking agent in the thermal curing.

\section{REFERENCES}

[1] Mammadov Sh. M. Fundamentals of synthesis, processing and vulcanization of nitrile-butadiene rubbers, ASOA, Baku, 2013

[2] Lia J., Oshima A., Miura T., Washio M., 2006. Preparation of crosslinked polythersulfone films by high-temperature electron-beam irradiation. Polymer Degradation and Stability, 91, 2867-2873

[3] Murakami K., Kudo H., 2007. Gamma-rays irradiation effects on polysulfone at high temperature. Nucl. Inst. and Methods in Physics Research, B265, 125-129.

[4] Makuushi K., 2003. An introduction to Radiation Vulcanization of Natural Rubber Latex. T. R. I. Global, Bangkok

[5] T. Yasin, S. Ahmed, F. Yoshii, K. Makuuchi, 2002. Radiation vulcanization of acrylonitrile-butadiene rubber with polyfunctional monomers. Reactive \& Functional Polymers. vo. 53 , pp 173-181.

[6] Zhu G., Xu S., Wang J., Zhang L., 2006. Shape memory behavior of radiation-crosslinked PCL/PMVS blends. Radiation Physics and Chemistry, 75. pp 443-448

[7] Wan J., Yoshi F., Makuushi K., 2000. Radiation vulcanization of ethylene-propylene rubber with polyfunctional monomer. Radiation Physics and Chemistry, 60. pp. $139-142$

[8] Ware T., Voit W., Gall K., 2010. Effect of sensitizer length on radiation crosslinked shape-memory polymers. Radiation Physics and Chemistry, 79. pp. 446-453

[9] Shen F., McKellop H.A., Salovey R., 1996. Irradiation of chemically crosslinked ultrahigh molecular weight polyethylene. Journal of Polymer Science, Part B: Polymer Physics, 24, 1063-1077.

[10] Su F., Huang H., 2010. Rheology and melt strength of long chain branching polypropylene by reactive extraction with various peroxides. Polymer Engineering\&Science, 50, $342-351$

[11] R.J. Woods, A.K. Pikayev, 1994. Applied radiation chemistry: radiation processing. J. Wiley, Science, p 535.

[12] Z. Holik, M. Danek, M. Manas, J. Cerny, M. Malachova,
2011. The Influence of Ionizing Radiation on Chemical Resistance of Polymers. Int. J. Of Mechanics, 3 (5): 210-17.

[13] F. Yoshii, K. Makuuchi, Kikukiwa S., Tanaka T., Saitoh J., Koyama K., 1996. High-melt-strength polypropylene with electron beam irradiation in the presence of polyfunctional monomers. Journal of applied Polymer Science, 60. pp 617-623.

[14] Lugao A, Artel B, Yoshiga A., Lima L., Parra D., Bueno J., Liberman S., Farrah M., Tercariol W., Otaguro H., 2007. Production of high melt strength polypropylene by gamma irradiation. Radiation Physics and Chemistry, 76. 1691-1695

[15] Auhl D., Stange J., Munstedt H., 2004. Long-chain branched polypropylenes by electron beam irradiation and their rheological properties. Macromolecules, 37. 9465-9472

[16] O'Keefe, Jerome F., 2004. Identification of polymers by IR spectroscopy. Rubber World, 230(3): p. 27.

[17] Roy Crompton, 2007. Determination of additives in polymers and Rubbers. Rapra Technology, p.68

[18] D.I. Bower, W.F. Maddams, 1992. The vibrational spectroscopy of Polymers. Cambridge University Press, $p$. 337.

[19] I. Reinholds, V. Kalkis, R.D. Maksimovs, 2012. The Effect of Ionizing Radiation and Magnetic Field on Deformation Properties of High Density

Polyethylene/Acrylonitrile-Butadiene Composites. J. Chem. Chem. Eng., 6 (3): 242-49.

[20] S. M. Mammadov, S.A. Rzayeva, A.A. Qaribov Study of the Structure and Parametres of Grid of Hydrogenated Butadiene Nitrile Rubber cross-linked with Polymer Peroxides. J. American Journal of Polymer Science 2012, 2(5), p.122-128

[21] S. M. Mammadov, E. O. Akperov, A. A. Qaribov Thermodynamic Research of Solubility of Irradiate Cross-linked Copolymers in Mix Butadiene nitrile with Polyvinylchloride. J. American Journal of Materials Science 2012, 2(6), p. 176-178

[22] S. M. Mammadov, E. O. Akperov, A. A. Qaribov The Influence of $\gamma$-Irradiation on Structuration in Solutions of BNR and Properties of Films. J. Open Journal of Physical Chemistry 2012, 2. p.182-184

[23] S. M. Mammadov, E. O. Akperov, A. A. Qaribov Study of İnfluence of Copolymer Neopren W and Vinyl Acetate on the Properties of Butadiene Nitrile Rubber. J. International Journal of Composite Material 2012, 2(6), 137-141

[24] S. M. Mammadov, S.A. Rzayeva, A.A. Qaribov Interactions of Sensitizer Disulfochloride Aromatic Compounds with Unsaturated Elastomers. J. International Journal of Advanced Chemical Technology 2013 v.2, p.6

[25] R.M. Morsy, M.N. Ismaiel, A.A. Yehia, 2013. Conductivity Studies on Acrylonitrile Butadiene Rubber Loaded with different types of Carbon Blacks. Int. J. of Materials, Methods and Technologies, 1, 4, pp22-35

[26] Jia. S, Jiang. P, Zhang Z., Wang Z., 2006. Effect of carbon-black treatment by radiation emulsion polymerization on temperature dependence of resistivity of carbon-black filled polymer blends. Radiation Physics and Chemistry., 75 , pp. 524-531

[27] Baccaro S., Cataldo F., Cecilia A., Padella F., Santini A., 
2003. Interaction between reinforce carbon black and polymer matrix for industrial applications. Nuclear Instrument and Methods in Physics Research, Section B, 208, pp.191-194

[28] Liu Y., Wu. G., Long D., Qi M., Zhu Z., 2005. ${ }^{60} \mathrm{Co}$ $\gamma$-irradiation initiated polymerization $\mathrm{n}$ ionic liquids - the effect of carbon chain length of monomer. Nuclear Instrument and Methods in Physics Research, Section B. 236, pp. $443-448$

[29] M. M. Hassan, R. O Aly, A. El-Ghandour, H. A. Abdelnaby, 2013. Effect of gamma irradiation on some properties of reclaimed rubber/nitrile-butadiene rubber blend and its swelling in motor and brake oils. J. of Elastomers and Plastics., vo. 45, no1,77-94.

[30] Robert S.M, Rebecca C, William S, David S, Mogon P., 2003. The effects of $\gamma$-radiation on the thermal, mechanical, and segmental dynamics of a silica filled, room temperature vulcanized Polysiloxane rubber. J. Polymer degradation and stability. 80(3), 51-59

[31] Guillaume T., Bernard B., Bruno A., 2011, Chemical reactions of polymer crosslinking and post-crosslinking at room and medium temperature. J. Progress in polymer science. 36(2), 191-217
[32] A Bhattacharya, 2000. Radiation and industrial polymers. J. Progress in polymer science. 25(3), 371-401

[33] Henly E., Johnson E. The Chemistry and Physics of high energy reactions, 1969 university press, p. 81

[34] Van Krevelen D. W. Properties of polymers correlations with chemical structure. Elsevien publishing company Amsterdam-London-New York. 1972 p. 415

[35] Кузнецов Е. В., Дивдин С. М., Бударина Л. А. Практикум по физике и химии полимеров. 1978 М. Химия с. $174-178$

[36] Brennan J.J., Jermin T.E. Rubb. Chem. Techn. 1987 v. 40, N3, p. 817

[37] Millans L. Tobin N. R Appl. Pol. Science, 1965, v. 9. p. 2993-3009

[38] Беллами Л. Инфракрасные спектры сложных молекул. Перевод с англ. М., ИЛ, 1973. стр. 389

[39] İvin K. J. Structural Studies of Macromolecules by Spectroscopic Methods, John Wiley. London-New York. 1980. p. $24-35$ 